\title{
Pseudoavoidance responses in two-way avoidance learning
}

\author{
DOROTHY E. McALLISTER and WALLACE R. McALLISTER \\ Northern Illinois University, DeKalb, Illinois 60115
}

\begin{abstract}
In a two-way avoidance learning task, responses sometimes occur during the CS-UCS interval prior to the initial receipt of shock. The number of such pseudoavoidance (PA) responses was found to be related positively to the number of avoidance responses made after the receipt of shock, implying that some of these avoidance responses were artifactual. The use of procedures that would decrease the occurrence of PA responses would also minimize this possible contamination of the avoidance data. Evidence was presented indicating that the frequency of PA responses was decreased when some amount of exploration of the apparatus, rather than none, was given prior to avoidance training, the shuttle compartments were separated by a small rather than a large guillotine door, a neutral rather than an intense auditory CS was used, and the CS-UCS interval was short (5 sec) rather than long (10 sec).
\end{abstract}

In previous investigations of two-way avoidance learning in this laboratory, it was rare to observe a subject locomote from one compartment to the other during the CS-UCS interval before the first shock was received. The compartments of the apparatus employed in these studies were separated by a small guillotine door resting on a hurdle, and the procedure involved some exploration of the apparatus prior to avoidance training. When the size of the door and the exploration treatment were altered in a recent study (McAllister, McAllister, Dieter, \& James, in press, Experiment 2), a large number of such responses were observed. The purpose of this paper is to present the data from the above study that relate to such pseudoavoidance (PA) responses, as well as to identify in other studies the experimental conditions that have led to such responses. Knowledge of the variables leading to PA responses would enable investigators to choose conditions that minimize their occurrence. This is important because, although a PA response does lead to the nonoccurrence (avoidance) of shock, it clearly is not made as a consequence of learning. Within two-factor theory, an avoidance response is assumed to be an escape-from-fear response. Obviously, a response made during the CS-UCS interval prior to the initial receipt of shock cannot be considered an escape from conditioned fear. Similarly, from a cognitive viewpoint (e.g., Seligman \& Johnston, 1973), an avoidance response made prior to the receipt of the first shock cannot be the result of the subject's expectancy that shock will occur if the response is not made.

This research was supported in part by Grant BMS71-00845 from the National Science Foundation and Grant MH-29232 from the National Institute of Mental Health. The authors thank Michael T. Scoles for several constructive suggestions regarding the manuscript. Requests for reprints should be sent to Dorothy E. McAllister, Psychology Department, Northern Illinois University, DeKalb, Illinois 60115.

\section{METHOD}

\section{Apparatus}

The apparatus employed is described fully in McAllister et al. (in press, Experiment 2). Briefly, it consisted of two identical compartments separated by a partition containing a guillotine door that rested on a hurdle $63 \mathrm{~mm}$ high. The door was $89 \mathrm{~mm}$ high and either $57 \mathrm{~mm}$ wide (small-door condition) or $125 \mathrm{~mm}$ wide (large-door condition). The grid floor in each compartment was hinged so that its depression operated a switch. Above each compartment was a box that served as a cover and contained two light sources. One source provided the intertrial illumination of $27 \mathbf{l x}$; the other provided the visual component of the compound CS, an increase in illumination to $980 \mathrm{~lx}$. The white-noise component of the CS was an increase in the ambient noise level in the apparatus from 50 to $61 \mathrm{~dB}$. The UCS was a discontinuous (.75 sec on and $2.00 \mathrm{sec}$ off), scrambled shock of $1.6 \mathrm{~mA}$ (nominal) provided by a GrasonStadler shock generator, Model 700.

\section{Subjects and Design}

The subjects were 96 naive female hooded rats, $114-120$ days of age, from the departmental colony. The first 24 subjects were in the small-door condition; the remaining 72 subjects were in the large-door condition. Four additional subjects were discarded, one because of experimenter error and three on the basis of a discard criterion described below. Within each sizeof-door condition, half of the subjects were exposed to the situational cues of the shuttlebox prior to avoidance training (preexposure, P) and half were not (no preexposure, NP).

\section{Procedure}

On each of the first four days of the experiment, subjects were brought to the experimental room in groups of four (two $P$ and two NP subjects). On each day, a $P$ and an NP subject were handled together (alternately picked up and petted and placed on a table to explore) for $2.5 \mathrm{~min}$ while the other two subjects remained in the carrying basket, after which the first pair was placed in the carrying basket while the second pair was handled. Then the $P$ subjects were exposed to the situational cues of the apparatus for $1 \mathrm{~h}$, while the NP subjects were placed in neutral holding boxes located adjacent to the shuttlebox. The subjects in the $\mathbf{P}$ condition were moved every $15 \mathrm{~min}$ from one shuttle compartment to the other, and the subjects in the NP condition were similarly moved from one holding box to the 
other. Thus, at the end of Day 4, each subject had received a total of $4 \mathrm{~h}$ of exposure to the situational cues of the apparatus or to the neutral holding boxes.

On Day 5 , all subjects received 10 two-way avoidance learning trials. Each trial began with the opening of the guillotine door and the simultaneous presentation of the compound CS. Shock was presented if the subject did not trip the floor switch in the opposite compartment within $5 \mathrm{sec}$ following CS onset. A response following shock onset terminated the CS and UCS (escape), whereas a response occurring during the 5-sec CS-UCS interval terminated the CS and prevented shock onset (avoidance). After a response, the door was closed, and the subject remained in the compartment it had entered for a 30-sec intertrial interval, after which the next trial was begun. Latencies were measured with a Hunter Klockounter in units of $.01 \mathrm{sec}$ from the opening of the guillotine door and CS onset to the depression of the floor in the opposite compartment.

Trials on which a shuttle response occurred before the first shock was received were not counted as avoidance learning trials. Three subjects, all in the NP large-door condition, were discarded for making four or more such PA responses.

Other details of the design and procedures are contained in McAllister et al. (in press, Experiment 2).

\section{RESULTS}

The results relating to the major purpose of the experiment, to investigate the effects of preexposure to the situational cues on two-way avoidance performance, are reported in McAllister et al. (in press, Experiment 2). Briefly, avoidance performance was significantly facilitated in the preexposed as compared to the nonpreexposed subjects. A serendipitous observation was that a large number of PA responses seemed to occur in the subjects not preexposed to the apparatus. In addition, there seemed to be a positive relationship between the occurrence of PA responses and the number of avoidance responses made after the receipt of the first shock. In order to evaluate this observation statistically, the data from the NP large-door condition were used because only in that condition were there a sufficient number of subjects and PA responses to provide a reasonable test. A $\chi^{2}$ test, with number of PAs $(0$ or $>0)$ placed orthogonal to number of avoidances $(0$ or $>0)$, was significant $\left[\chi^{2}(1)=4.63, p<.05\right]$. One or more avoidance responses occurred more frequently in the 10 trials when one or more PAs had also occurred (10 of 12 subjects, $83 \%$ ) than when no PAs had occurred (11 of 24 subjects, $46 \%$ ). A further question that cannot be answered by the present data, because of the limited number of trials administered, is whether this relationship holds also for later stages of avoidance training.

Two variables that seemed to affect the number of PA responses in the present experiment were the preexposure treatment and the size of the door between the shuttle compartments. The effect of the preexposure treatment was first evaluated using the subjects in the large-door condition. In the 72 subjects, 26 PAs occurred (21 NP, 5 P) distributed among 16 subjects, excluding the 3 subjects who were discarded for making what was considered an excessive number of PAs (6, 7 , and 10 , all NP). A $\chi^{2}$ test, with P vs. NP placed orthogonal to number of PAs $(0$ and $>0)$, allowed the rejection of the null hypothesis $\left[\chi^{2}(1)=5.14, p<.05\right]$, indicating that PAs occurred more frequently in the NP condition. The percentage of subjects making one or more PAs was $33 \%$ (12 of 36 subjects) in the NP condition and $11 \%$ ( 4 of 36 subjects) in the $P$ condition. The effect of preexposure could not be evaluated for the small-door condition because only one. PA occurred (NP condition) in the 24 subjects. However, data from 64 subjects are available from another study conducted in this laboratory under the same conditions as employed in the small-door treatment of this experiment (Dieter, 1977). A $\chi^{2}$ test, identical to that used for the largedoor data above, was significant $\left[\chi^{2}(1)=4.01, p<.05\right]$. Again, PA responses were more frequent in the NP ( 6 of 32 subjects, 19\%) than in the $P$ condition (1 of 32 subjects, $3 \%$ ).

The above data indicate that the frequency of PA responses was greater with the large than with the small door. A direct evaluation of the effect of door size on PA responses was made separately for each preexposure condition. A $\chi^{2}$ test with size of door (small vs. large) placed orthogonal to number of PA responses $(0$ or $>0)$ indicated that under the $\mathrm{P}$ condition the variables were not significantly related $\left[\chi^{2}(1)=1.45, p>.20\right]$, although PA responses occurred more frequently when the door was large $(11 \%)$ than when it was small $(0 \%)$. Under the NP condition, the relationship between the variables approached significance $\left[\chi^{2}(1)=2.85\right.$, $.05<\mathrm{p}<.10]$. This test can, however, be considered to be biased against finding a relationship because the three subjects discarded on the basis of the PA criterion were all from the NP large-door condition. Including their data in the analysis yielded significance $\left[\chi^{2}(1)=\right.$ $3.87, \mathrm{p}<.05$ ], with PA responses being made by $38 \%$ of the subjects in the large-door condition and $8 \%$ of the subjects in the small-door condition.

The duration of the preexposure treatment used in the present experiment was $4 \mathrm{~h}$. Data from this laboratory suggest that such a long preexposure treatment is not required to minimize the occurrence of PA responses. For example, the subjects in the McAllister, McAllister, and Dieter (1976) and the McAllister, McAllister, and Douglass (1971) studies were given only 20 min of exploration (10 min in each compartment) prior to two-way avoidance training in the small-door apparatus. Considering all the subjects of the McAllister et al. (1971) study and all the subjects who locomoted to a lighted compartment in the McAllister et al.(1976) study (i.e., omitting subjects who entered a dark compartment), there were 220 subjects. Of these, only four made a PA response (2\%), which approximates the percentages reported above for the $\mathrm{P}$ small-door condition of Dieter's (1977) study and of the present experiment (3\% and $0 \%$, respectively). A similar result 
holds for the large-door condition. The percentage of PA responses that occurred in the present experiment in the P large-door group (11\%) is comparable to the $13 \%$ (6 of 45 subjects) that occurred following $20 \mathrm{~min}$ of exploration in a recently completed unpublished experiment in this laboratory conducted under otherwise comparable conditions.

Data from a number of other sources demonstrate the effect of additional variables on the occurrence of PA responses. One such variable is the intensity of the CS. Bauer (1972) found that with an $80-$ or $90-\mathrm{dB}$ white noise as the CS in a two-way avoidance task, $35 \%-40 \%$ of the subjects made a PA response on the first trial, whereas no PAs occurred when the CS intensity was $70 \mathrm{~dB}$. These data are consistent with those of Cicala and Ulm (1971), who found that in subjects that never received shock the number of crossings from one side of a test box to the other was greater in the presence of an 80-dB white noise than in its absence. These results are not surprising because intense noise has been shown to be aversive (e.g., Campbell \& Bloom, $1965)$ and can serve as the UCS in two-way avoidance learning (Hughes \& Brett, 1976). Other data (Moltmann, 1979) suggest that the length of the CS-UCS interval may also be an important determinant of the number of PA responses. In her study, which used the large-door apparatus of the present experiment, all subjects explored each compartment for $5 \mathrm{~min}$ prior to avoidance training with a 10-sec CS-UCS interval. It was found that 51 of 121 subjects (42\%) made one or more PA responses. However, had a 5-sec CS-UCS interval been employed, only six of the subjects $(5 \%)$ would have been classified as having made a PA response. That is, the PA responses occurred mainly with a latency between 5 and $10 \mathrm{sec}$. These data imply that the large number of PA responses normally found with the largedoor condition and no preexposure, as in the present experiment, can be reduced with as little as $10 \mathrm{~min}$ of exploration as long as a short CS-UCS interval is employed. Additionally, Modaresi (1978) found that the large number of PA responses usually obtained in his two-way avoidance apparatus was markedly reduced by the use of a relatively high hurdle between compartments.

\section{DISCUSSION}

Investigators studying avoidance learning are presumably interested in determining the basis or bases for the acquisition and maintenance of the avoidance response. Therefore, it would seem obvious that responses occurring before receipt of the first shock should not be included in the data as avoidance responses. Furthermore, because of the correlation between the occurrence of PA responses and the number of avoidance responses, at least early in training, there is the suggestion that some of the avoidance responses made after the receipt of the first shock might be artifactual. That is, they may be occurring for the same reason that PA responses occur and not because of the contingent relationships among the stimuli and responses constituting the avoidance task. If such is the case, the picture of the development of avoidance responding shown by the acquisition curve may be distorted. In addition, if experimental groups receive differential treatments that produce different numbers of PA responses, an evaluation of the effect of the manipulated variable on avoidance performance would be contaminated by the inflated avoidance responding that is correlated with PA responding.

A simple solution for these problems is to use procedures that minimize the occurrence of PA responses. The data presented above indicate several such procedures: providing some amount of exploration of the apparatus prior to avoidance training, using a relatively small guillotine door or a high hurdle between the shuttle compartments, employing a neutral (not intense) CS, and using a short (5-sec) CS-UCS interval.

\section{REFERENCES}

BAUER, R. H. The effects of CS and US intensity on shuttlebox avoidance. Psychonomic Science, 1972, 27, 266-268.

Camprell, B. A., \& Bloom, J. M. Relative aversiveness of noise and shock. Journal of Comparative and Physiological Psychology, 1965, 60, 440-442.

Cicala, G. A., \& Ulm, R. R. The effects of prefear conditioning shock intensity on initial shuttle response rate. Psychonomic Science, 1971, 23, 67-68.

Dieter, S. E. Preexposure to situational cues and shock intensity in two-way avoidance learning. Animal Learning \& Behavior, 1977, 5, 403-406.

Hughes, R. A., \& BRETT, C. W. Shuttlebox avoidance to intense white noise: Acquisition and the Kamin effect in rats. Animal Learning \& Behavior, 1976, 4, 33-36.

McAllister, D. E., McAllister, W. R., \& Dieter, S. E. Reward magnitude and shock variables (continuity and intensity) in shuttlebox-avoidance learning. Animal Learning \& Behavior, 1976, 4, 204-209.

McAllister, W. R., McAllister, D. E., Dieter, S. E., \& JAMES, J. H. Preexposure to situational cues produces a direct relationship between two-way avoidance learning and shock intensity. Animal Learning \& Behavior, in press.

McAllister, W. R., McAllister, D. E., \& Douglass, W. K. The inverse relationship between shock intensity and shuttle-box avoidance learning in rats: A reinforcement explanation. Journal of Comparative and Physiological Psychology, 1971, 74, 426-433.

MODARESI, H. A. Facilitating effects of a safe platform on two-way avoidance learning. Journal of Experimental Psychology: Animal Behavior Processes, 1978, 4, 83-94.

Moltmann, M. L. Independent measurement of fear at different stages of two-way avoidance learning. Unpublished master's thesis, Northern Illinois University, 1979.

Seligman, M. E. P., \& Johnston, J. C. A cognitive theory of avoidance learning. In F. J. McGuigan \& D. B. Lumsden (Eds.), Contemporary approaches to conditioning and learning. Washington, D.C: Winston, 1973.

(Received for publication January 31, 1979.) 